\title{
A Review of Floc Strength and Breakage
}

4

5

P. Jarvis ${ }^{1}$, B. Jefferson ${ }^{1}$, J. Gregory ${ }^{2}$ and S. A. Parsons ${ }^{1 *}$

6

*corresponding author

7

$8{ }^{1}$ School of Water Sciences, Cranfield University, Cranfield, Bedfordshire, MK40 OAL,

9

10

11

12

13

14

15

16

17

18

19

20

21

22

23

24

25
$U K$.

(phone: +44 1234 754841, fax: +44 1234 751671, e-mail:

s.a.parsons@,cranfield.ac.uk)

${ }^{2}$ Dept. of Civil and Environmental Engineering, University College London,

Gower Street, London WC1E 6BT, UK

\section{列}

5

6

7

8

9


2 The main focus of the paper is to review current understanding of floc structure and

3 strength. This has been done by reviewing current theoretical understanding of floc

4 growth and breakage and an analysis of different techniques used for measuring floc

5 strength. An overview has also been made of the general trends seen in floc strength

6 analysis. The rate of floc formation is a balance between breakage and aggregation

7 with flocs eventually reaching a steady state size for a given shear rate. The steady

8 state floc size for a particular shear rate can therefore be a good indicator of floc

9 strength. This has resulted in the development of a range of techniques to measure

10 floc size at different applied shear levels using a combination of one or more of the

11 following tools: light scattering and transmission; microscopy; photography; video

12 and image analysis software. Floc strength may be simply quantified using the initial

13 floc size for a given shear rate and the floc strength factor. More complex techniques

14 have used theoretical modelling to determine whether flocs break by large scale

15 fragmentation or smaller scale surface erosion effects, although this interpretation is

16 open to debate. Impeller based mixing, ultrasound and vibrating columns have all

17 been used to provide a uniform, accurate and controllable dissipation of energy onto a

18 floc suspension to determine floc strength. Other more recent techniques have used

19 sensitive micromanipulators to measure the force required to break or compress

20 individual flocs, although these techniques have been limited to the measurement of

21 only a few hundred flocs. General trends emerge showing that smaller flocs tend to

22 have greater strength than larger flocs, whilst the use of polymer seems to give

23 increased strength to only some types of floc. Finally, a comparison of the strength of

24 different types of floc (activated sludge flocs, organic matter flocs, sweep flocs and 
1 charge neutralised flocs) has been made highlighting differences in relative floc 2 strength.

3

4 Key words:

$5 \quad$ Floc, breakage, growth, re-growth, shear, strength

6 


\section{Introduction}

2 Floc strength is a particularly important operational parameter in solid/liquid

3 separation techniques for the efficient removal of aggregated particles. Unit processes

4 at water treatment works (WTW) are generally designed to minimise floc breakage,

5 however in reality often this is not the case, with regions of high shear being

6 prevalent (McCurdy et al., 2004). This may include regions around the impeller zone

7 of flocculating tanks, processes such as dissolved air flotation (DAF) or transfer over

8 weirs and ledges and through pumps. Flocs are therefore exposed to a range of

9 stresses. Flocs must resist these stresses if they are to prevent being broken into

10 smaller particles. In an operational sense, this is important because small particles

11 generally have lower removal efficiencies (Boller and Blaser, 1998). Smaller particles

12 will generally settle more slowly than larger particles of similar density. Flocs formed

13 for removal in dissolved air flotation that subsequently break up into many smaller

14 parts may be captured less efficiently by air bubbles. In addition, flocs that are

15 removed using membrane filtration will foul membranes if small pieces of floc break

16 off and plug membrane pores.

18 Floc strength is dependent upon the interparticle bonds between the components of 19 the aggregate (Parker et al., 1972; Bache et al., 1997). This includes the strength and 20 number of individual bonds within the floc. Therefore a floc will break if the stress

21 applied at its surface is larger than the bonding strength within the floc (Boller and 22 Blaser, 1998). Increased floc compaction is considered to increase floc strength due to 23 an increase in the number of bonds holding the aggregate together. Leentvaar and 24 Rebhun (1983) also list the size and shape of floc microparticles as being an 25 important consideration for floc strength. 
1 However, the development of a satisfactory technique to quantify floc strength has

2 proven to be difficult. This is partly due to the inherent complexity, fragility and

3 variation in floc size, shape and composition and also due to a generally accepted

4 view that there are two modes of floc rupture (Parker et al., 1972; Francois, 1987;

$5 \quad$ Yeung and Pelton, 1996; Mikkelsen and Keiding, 2002). These have been classified

6 as surface erosion and large-scale fragmentation. Surface erosion is the removal of

7 small particles from the floc surface resulting in an increase in the small particle size

8 ranges. Large scale fragmentation is the cleavage of flocs into pieces of a similar size

9 without an increase in primary particle concentration. The problem of describing

10 strength arises from the fact that these two rupture modes are thought to be caused by

11 different stresses (Yeung and Pelton, 1996). Fragmentation is thought to occur from

12 tensile stress acting normally across the whole floc, whilst erosion is due to the

13 shearing stress acting tangentially to the floc surface (Figure 1). In addition there are

14 complex interpretations of floc strength data arising from relative eddy size which

15 will be discussed in later sections.

17 A review of the literature shows there to be no established standardised floc strength

18 test, although a number of techniques have been evaluated. Floc strength may be

19 broadly considered in terms of the energy required to break flocs under tension, 20 compression or shear (Zhang et al., 1999). However, finding ways of quantifying the

21 energy input for floc breakage has not been easy. There is therefore a need for a more

22 thorough understanding of how floc strength can be measured and what information

23 can be found from floc strength tests. This paper aims to review current knowledge

24 on floc formation and breakage, the different techniques used to measure strength for 25 a range of flocs including activated sludge flocs, inorganic metal flocs, natural 
1 organic matter flocs and flocs formed from ionic salts. Particular emphasis has been

2 placed on the applied shear rate, since most previous research has been concerned

3 with this aspect of floc strength. Finally, the review looks at the interpretation of floc

4 strength information.

\section{2. Floc formation and breakage}

7 Floc strength is directly related to floc structure and is therefore highly dependent

8 upon the floc formation process. The combined processes of coagulation and

9 flocculation aim to increase particle size for increased removal efficiency of very

10 small particles, colloids and micro-pollutants. Coagulation is the process of

11 chemically changing colloids so that they are able to form bigger particles by coming

12 close to one another. This may be achieved by particle destabilisation by double layer

13 compression or physical enmeshment of colloids within coagulant precipitates or

14 chemical reaction or chemical sorption (Cornwell and Bishop, 1983). Flocculation is

15 the process of transferring coagulated colloids into contact with each other to form

16 larger aggregates (Klimpel and Hogg, 1991; Gregor et al., 1997). The exact process

17 of particle destabilisation and the subsequent colloid aggregation is complex. It is

18 generally considered to be a two stage process of particle transport and particle

19 attachment (Armirtharajah and O’Melia, 1990). Agglomerating particles must firstly

20 collide with each other and secondly must adhere upon collision. Gregory (1989)

21 treats these steps as being independent and separate from one another. However, flocs

22 do not continue growing and reach a steady state size for a given shear condition. It

23 has been generally accepted that floc growth is held in check by floc breakage so that

24 the rate of aggregation is considered a balance between floc formation and floc 25 breakage (Parker et al., 1972; Francois, 1987; Spicer and Pratsinis, 1996; Ducoste and 
1 Clark, 1998; Biggs and Lant, 2000). The stability of flocs in suspension is therefore

2 dependent upon how easy they are to break with aggregate breakage being directly

3 related to the strength and number of the bonds holding the floc together. During the

4 rapid initial formation of microflocs aggregation dominates over floc breakage,

5 however the importance of breakage increases as floc size increases until a steady

6 state floc size distribution is reached. Thus the steady state floc size is governed by

7 the prevailing shear/stress conditions within the containing vessel. The rate of particle

8 collision and the nature of the particle interactions are fundamental to the rate of floc

9 growth $\left(R_{\text {floc }}\right)$ and may be summarised as in Equation 1 as the difference between the

10 the rate of aggregation and the rate of floc breakage $\left(R_{b r}\right)$. The former can be written

11 as the rate of particle collision, $R_{c o l}$ and a collision efficiency factor, $\alpha$. The factor $\alpha$ is

12 the fraction of collisions which result in attachment. Thus the overall rate of floc

13 growth may be written as:

$14 \quad R_{\text {floc }}=\alpha R_{c o l}-R_{b r}$

Equation 1

15 When the two terms on the right hand side of equation 1 are equal, the net rate of floc 16 growth is zero and the floc size attains a limiting value. The collision efficiency is not 17 constant, but depends on the effective shear rate and particle size. For given shear 18 conditions $\alpha R_{c o l}$ decreases as the particle (floc) size increases as the number of 19 particles in the system is reduced. This is another reason why flocs reach a limiting 20 size (Brakalov, 1987). Another important consideration is that floc breakage may be 21 irreversible to some extent, so that broken fragments do not readily re-form (Francois, 22 1987; Spicer et al., 1998; Gregory and Dupont, 2001). For irreversible breakage the 23 collision efficiency will be reduced and, for completely irreversible breakage $\alpha .=0$. 
1 To summarise floc formation and breakage, flocculating suspensions are governed by

2 the prevailing shear conditions and will reach a steady state. When the shear rate

3 increases above a critical level flocs will break until a new steady state is reached. In

4 some cases, because of the irreversible nature of floc breakage, flocs are unable to re-

5 grow if broken at a higher shear rate. Measuring the shear energy required to break

6 individual flocs or those in a suspension is therefore of high operational importance.

\section{Measuring floc strength}

9 Two fundamental approaches have been taken in measuring floc strength; a 10 macroscopic measure of the energy required in a system for floc breakage and a 11 microscopic approach that measures the inter-particle forces within individual flocs. 12 A brief summary of these techniques is shown in Table 1. Due to the fact that the 13 applied shear rate determines floc size, most work on floc strength has been in the 14 macroscopic field, using applied shear techniques.

\subsection{Macroscopic floc strength tests}

17 Macroscopic floc strength tests have arisen from the relationship between the applied 18 hydrodynamic shear rate and the resulting floc size. Under low shear rate conditions, 19 particles may be encouraged to aggregate, but, under increased shear rate, aggregate 20 break-up is observed (Mikkelsen and Keiding 2002). Floc size is therefore a dynamic 21 equilibrium between floc break-up and aggregation. Gregory (2003) states that when 22 comparing different flocs, the size (or flocculation index) for a given shear rate 23 indicates floc strength. Whilst this is the case for the given shear condition under 24 which the flocs were formed, it does not give an indication of how flocs will behave upon exposure to an increased shear rate, as could occur at a WTW when flocs are 
1 transferred from flocculators or to higher shear treatment processes such as DAF or

2 high rate filtration. For this reason, floc strength can be measured by applying an

3 increased shear rate or a normal stress to the formed aggregates and relating the

4 energy dissipation or velocity gradient applied to the maximum or average floc size

5 remaining (Yeung et al., 1997, Boller and Blaser, 1998 and Lee and Liu, 2001). The

6 major problem to overcome with these techniques is the fact that the energy

7 dissipation is never homogenously distributed in the test vessel.

9 The majority of macroscopic floc strength tests have used impeller-based systems

10 whereby a known shear rate is applied to a grown floc suspension within a vessel of

11 between 1-4 L volume. However the geometry of the vessel and impeller type varies 12 between the techniques (Table 2). The breakage behaviour of flocs is monitored by 13 following at changes in floc size over a range of shear rates. As can be seen, the range 14 of shear rates investigated varies from study to study. The method of floc size 15 determination is crucial and varies between techniques. It is important to ensure that 16 the technique used to measure floc size does not act to damage the aggregates due to 17 their highly fragile nature. Most of the techniques listed aim to be as non-destructive 18 as possible, although some rely upon taking flocs from the containing vessel and 19 observation using microscopy and image analysis (Wu et al., 2003). However it is 20 difficult to imagine that removing flocs in this manner cannot damage and break the 21 floc particles. The remaining methods have been with commercial particle size 22 instruments that use light scattering to determine particle size (Francois, 1987; Spicer 23 et al., 1998; Biggs and Lant, 2000) or from analysis of video frames or photographs 24 using image analysis (Leentvaar and Rebhun, 1983; Bache et al., 1999; Bouyer et al., 25 2001; Bache and Rasool, 2001). 
1 The light scattering instruments measure particle size by passing a laser beam through

2 a suspension of particles. These techniques rely upon a constant flow of the

3 suspension through the instrument during the measurement cycle (Farrow and

4 Warren, 1993). This feature has been harnessed to allow the development of a less

5 destructive methodology for measuring floc size (Spicer et al., 1998; Biggs and Lant,

6 2000). These methods have a stirred vessel containing the aggregate suspension and

7 are connected to the particle sizing device by plastic tubing. Intrinsic to this type of

8 system is a requirement to pump the suspension through the optical unit of the size

9 analyser. Spicer et al. (1998) compared 3 types of pumping techniques for delivery to

10 the optical cell: a peristaltic pump, a syringe pump and a hand pipette. They

11 concluded that a continuous recycle using a peristaltic pump on the return side of the 12 measuring cell was the least severe technique on the flocs and allowed easy 13 continuous monitoring of the suspension. However, the problems of pumping can be 14 removed by sending the suspension to waste after making a measurement to 15 overcome any issues involved in a continuous recycle system (Francois, 1987). This 16 in itself is problematic as the volume of the suspension is continuously decreasing 17 and will affect the velocity gradients within the containing vessel, which will 18 therefore not be constant over the duration of the experiment, so most workers have 19 favoured a continuous loop.

21 Similar dynamic systems have been employed using the PDA to give an indication of 22 floc size (Burgess et al., 2000; Gregory and Dupont, 2001; Yukselen and Gregory, 23 2004; McCurdy et al., 2004). In this technique, a narrow light beam is passed through 24 a flowing suspension. The transmitted light intensity (dc value) is measured along 25 with the root mean square value of the fluctuating component (rms). A ratio of the 
1 rms:dc gives a very sensitive indication of particle aggregation and is known as the

2 previously mentioned flocculation index. The PDA is reported to be a very good and

3 easy to use comparative tool showing qualitative changes in floc aggregation

4 (Gregory and Nelson, 1986). However, the instrument is unable to give an absolute

5 particle size for comparison with other techniques. In addition, the FI is an indicator

6 of both particle size and particle number (McCurdy et al., 2004). As such there is no

7 way of knowing the precise contribution of each of these components in the final FI

8 value. However, aggregate size is probably the over-riding factor as previous work

9 has shown that when flocs grow larger the FI value always increases.

11 A combination of photography/video and image analysis has also been widely used to 12 monitor floc suspensions, such that a flocculated suspension can be observed by 13 capturing images of a stirred suspension by focusing on a plane a short distance $(0.3-$ $141 \mathrm{~cm}$ ) behind the wall of vessel containing the suspension (Leentvaar and Rebhun; 15 1983; Ducoste and Clark, 1998; Chakraborti et al., 2000; Bache and Rasool, 2001). 16 Calibration is achieved by focusing on a graticule suspended into the tank prior to 17 flocculation experiments. The advent of powerful digital and CCD cameras and 18 comprehensive image analysis software has allowed much quicker measurements of 19 an almost inexhaustible number of different floc size measurements to be made from 20 floc samples (Wang et al., 2002).

22 For measuring floc size, no particle size method can be considered ideal. Aggregates 23 are highly irregular and porous and so their scattering patterns are likely to be very 24 different than for equivalent solid spheres of the same material in light scattering 25 devices. Although the light scattering properties of aggregates have yet to be fully 
1 quantified, Farrow and Warren (1993) conclude that, similar to the PDA device,

2 light/laser scattering and transmission techniques are good for showing qualitative

3 (rather than absolute) changes in floc size for aggregation systems. In addition their

4 capability for measuring a very wide range of floc sizes (20 nm to $2 \mathrm{~mm}$ ) makes them

5 very suitable for monitoring flocs and colloidal systems, although the expense of

6 these instruments limits their wide-scale application. In the previously mentioned set-

7 ups, the inclusion of the measuring instrument will undoubtedly change the shear

8 profile in the containing vessel and as such may inadvertently affect the floc size.

9 Photographic techniques are good in this respect, because the flocs are only exposed

10 to the shear rate of the impeller in the containing vessel and do not have to pass

11 through a pumped system. The limitations of photography are the time and care that 12 must be taken in preparing complex background lighting arrangements to allow for

13 suitable contrast between floc and background. Furthermore, very small flocs may be 14 missed that are beyond the detection limits of the camera being used thus biasing 15 towards the detection of large particles (Leentvaar and Rebhun, 1983). Bache et al. 16 (1999) concluded that floc sizes below $30 \mu \mathrm{m}$ could not be reliably measured using 17 their camera system. This limitation may prevent the detection of floc erosion 18 mechanisms as the small eroded particles may be missed by the technique. Masking 19 effects can also occur in very concentrated floc suspensions. Given these constraints, 20 care must be taken when comparing floc size data obtained from different 21 methodologies.

24 One of the simplest evaluations of floc strength is the calculation of a floc strength 25 factor (Francois, 1987 and Govereanu, 1987). This is effectively the ratio of floc size 
1 after and before breakage at a particular shear rate and may be calculated as shown in

2 Equation 2 in Table 1.

4 The higher the value of the strength factor, the less sensitive the flocs are to breakage

5 as a result of increased shear rate and are therefore considered stronger. The strength

6 factor is not a constant and changes depending upon the applied shear rate during

7 rupture and so strength factors can only be compared for similar breakage conditions.

8 Francois (1987) noted an increase in the strength factor from 23.9 to 29.3 for kaolin

9 flocs formed with longer rapid mix times between 0-360 s and an increase in strength

10 factor from 17.5 to 26.5 for flocs formed with increased slow stir shear rate between

$1121-54 \mathrm{~s}^{-1}$. A breakage shear rate of $1396 \mathrm{~s}^{-1}$ for 1.5 minutes was applied in these

12 experiments. Fitzpatrick et al. (2003) compared the strength factor of kaolin flocs

13 and observed the impact of temperature $\left(6-29^{\circ} \mathrm{C}\right)$ on floc strength using a PDA and a

14 breakage shear rate of $520 \mathrm{~s}^{-1}$ for 10 seconds. Whilst the PDA does not give an

15 absolute floc size, the FI value before and after breakage can be used as a surrogate

16 for $d(1)$ and $d(2)$. Floc strength has been seen to decrease with increasing 17 temperature. For example, the floc strength factor decreased from 21 to 14 for alum-

18 kaolin flocs dosed at $3.4 \mathrm{mg} \mathrm{L}^{-1} \mathrm{Al}$ over the experimental temperature range 19 (Fitzpatrick et al., 2003). A general trend was seen that showed floc strength 20 decreased with increasing floc size, such that flocs formed at the original slow stir 21 that had a high FI value had lower floc strength factors than those of lower FI value.

23 A comparison of kaolin floc strength factors for a range of different coagulants has 24 shown that hydrolysing coagulants such as alum and polyaluminium chloride (PAX 
1 XL-9) give lower floc strength than cationic polyelectrolytes (polyDADMAC and

2 Zetag 64) (Yukselen and Gregory, 2004).

4 The floc strength factor allows a relatively quick and easy method of determining a

5 floc strength value and indicates how small a floc will become relative to its previous

6 size for a given increase in shear rate. However, as the breakage shear rate and mixer

7 characteristics are invariably different between different studies it is hard to directly

8 compare the results other than for general trends. There has been little work showing

9 how the relationship between the floc strength factor changes with increasing

10 breakage shear rate. More work needs to be done in this area to give a better

11 comparison of floc strength using the strength factor and on a wider range of

12 suspensions other than kaolin in order to compare strength values between different

13 coagulated systems for a standardised breakage shear rate.

\section{3.1.2. Shear based floc strength and breakage models}

16 Shear based floc strength models have evolved from strong empirical evidence

17 showing that the final floc size distribution is related to the applied shear rate (Parker

18 et al., 1972; Spicer et al., 1998). Shear has usually been characterised by the average

19 velocity gradient as shown in Equation 9 for homogenous and isotropic turbulence

20 (Camp and Stein, 1943).

$21 \quad G=\sqrt{\frac{\varepsilon}{v}} \quad$ Equation 9

$22 G$ is the average velocity gradient $\left(\mathrm{s}^{-1}\right) ; \varepsilon$ is the rate of energy dissipation per unit mass of fluid $\left(\mathrm{N} \mathrm{m} \mathrm{s}^{-1}\right.$

$\left.23 \mathrm{~kg}^{-1}\right)$ and $v$ is the kinematic viscosity $\left(\mathrm{m} \mathrm{s}^{-1}\right)$.

25 The energy dissipation term is given by Equation 10. 


$$
1 \quad \varepsilon=\frac{P_{0} N^{3} D^{5}}{V}
$$

\section{Equation 10}

$2 \varepsilon$ is the energy dissipation per unit mass of fluid $\left(\mathrm{N} \mathrm{m} \mathrm{s}^{-1} \mathrm{~kg}^{-1}\right) ; P_{0}$ is the impeller power number; $N$ is

3 the impeller speed (rps); $V$ is the stirred tank volume $\left(\mathrm{m}^{3}\right)$ and $D$ is the impeller diameter $(\mathrm{m})$.

4

5 Due to the relationship between the velocity gradient in the flocculating vessel and 6 aggregate size, Parker et al. (1972) suggested an empirical expression for the stable 7 floc size (Equation 11).

$9 \quad d=C G^{-\gamma}$

\section{Equation 11}

$10 d$ is the floc diameter $(\mathrm{m}) ; C$ is the floc strength co-efficient; $G$ is the average velocity gradient $\left(\mathrm{s}^{-1}\right)$ and

$11 \gamma$ is the stable floc size exponent.

12

13 Linearization of the equation allows values of $\gamma$ and $\log C$ to be found from a $\log -\log$

14 plot of floc size measurement against the average velocity gradient (Equation 12).

18 There is some argument in the literature as to whether the maximum floc size 19 remaining in the system should be measured or the average floc size. The initial 20 empirical observations relate the shear rate to the maximum particle size $\left(d_{\max }\right)$, as in 21 Equation 3 (Table 1). Bache et al. (1999) used the $95 \%$ floc diameter obtained using 22 an external video camera. This was done to remove problems associated with 23 resolution when measuring smaller floc sizes using this technique. However, both 24 Leentvaar and Rebhun, (1983) and Francois (1987) concur that the same relationship 
1 is seen when using average floc diameters. When the values of $\gamma$ have been compared

2 for the mean, median and maximum floc size for the same coagulation conditions $\gamma$

3 remained fairly constant - between 0.43 and 0.49 - for all three floc sizes (Leentvaar 4 and Rebhun, 1983).

6 The value of $\log C$ strongly depends upon the method used for particle size 7 measurement and which characteristic value of $d$ has been used. As there has been 8 wide variation between different studies, $\log C$ can only be used to compare of floc 9 strength within specific experimental systems. However, as the value of $\gamma$ remains 10 relatively constant whichever value of $d$ has been used it is a useful value for 11 comparing floc strength and break-up.

13 The steeper the slope $\gamma$, the greater the reduction in floc size is seen with increasing $14 G$. The curves shown in Figure 2 are three theoretical examples of different floc 15 suspensions formed at a slow stir of $G_{\text {init }}$ showing different resistance to floc break16 up. One interpretation of the data is to consider the steepness of the slope as an 17 indicator of floc strength. For example, considering line (a) the slope of the line is 0 18 and floc size is independent of the applied shear rate. The flocs do not break upon 19 exposure to shear and as such must be considered strong flocs. If the slope of the line 20 is shallow as in line (b) then these flocs are better able to resist shear than the 21 example in (c). Therefore flocs (b) should be considered stronger than flocs (c) as the 22 average/maximum floc size does not decrease so rapidly. However, this is likely to be 23 an over-simplification of the situation. Many workers ascribe the value of $\gamma$ to the 24 dominant mode of floc degradation from both theoretical and experimental analysis 25 and increasing values of $\log C$ as an indicator of increased floc strength (Parker et al., 
1 1972; Leentvaar and Rebhun, 1983; Francois, 1987). Solving complex equations to

2 describe floc break-up and turbulence patterns, Parker et al. (1972) were the first to

3 theoretically describe the impact shear has on floc size. These types of models assume

4 flocs are composed of mono-disperse primary particles and characterise eddy

5 frequency and breakage capacity.

6

7 The theoretical basis of the value $\gamma$ may be explained by turbulent shear patterns 8 relative to eddy size (Biggs and Lant, 2000; Bache 2004). In most flocculation 9 processes, conditions are generally considered to be turbulent (Francois, 1987; Boller 10 and Blaser, 1998). Eddy viscosity is the proportionality factor describing the turbulent 11 transfer of energy as a result of moving eddies, giving rise to tangential stresses. This 12 is analogous to molecular viscosity in laminar flow where liquids resist flow as a 13 result of intermolecular friction, therefore, when a liquid moves, energy is dissipated 14 in a tangential direction to the moving viscous fluid. This energy is commonly 15 referred to as viscous dissipation. Inertial convection is the release of energy in an 16 outward direction, normal to the rotational eddy flow. Levich (1962) described 17 turbulence using a scale whereby turbulent flow is described by the velocity and size 18 of eddies. Very large eddies are responsible for the mixing of the system with little 19 energy dissipation and therefore do not rupture or break flocs, whilst smaller eddies 20 are responsible for most of the energy dissipation. The Kolmogoroff microscale 21 describes the length scale $(\eta)$ of the energy-dissipating eddies (Equation 13).

$22 \quad \eta=\left(\frac{\mu^{3}}{\varepsilon}\right)^{\frac{1}{4}}$ Equation 13

$23 \eta$ is Kolmogoroff's microscale of turbulence (m); $\mu$ is viscosity $\left(\mathrm{kg} \mathrm{m}^{-2} \mathrm{~s}^{-1}\right)$ and $\varepsilon$ is the energy 24 dissipation $\left(\mathrm{N} \mathrm{m} \mathrm{s}^{-1} \mathrm{~kg}^{-1}\right)$. 
1 Inertial convection is responsible for energy dissipation of the larger eddies within the

2 microscale range, whilst viscous energy is responsible for the energy dissipation of

3 the smaller eddies in this range (Figure 3).

5 At high energy inputs, the value of the micro-scale $\eta$ is of a similar order of 6 magnitude to the floc sizes whilst at low velocity gradients it is much larger, which

7 helps to explain why flocs become more prone to breakage at high velocity gradients.

8 However, it is difficult to say which eddies are responsible for floc breakage as it the

9 floc break-up is highly dependent on the eddy size relative to the floc size. Under 10 normal flocculator conditions, viscous effects dominate (Boller and Blaser, 1998).

11 Some authors suggest that when flocs are smaller than the micro-scale they become 12 prone to breakage by surface erosion, whilst above the microscale flocs are thought to 13 be more exposed to breakage by fracture (Thomas et al., 1999). Other theoretical 14 analysis suggests that when flocs are in the viscous energy region (i.e. below the 15 critical microscale eddy size) values of $\gamma$ of 0.5 have been calculated to indicate floc 16 fragmentation, whilst erosion mechanisms are dominant if $\gamma=1$. In the inertial 17 convection zone a value of $\gamma=0.5$ suggests large scale fragmentation events and $\gamma=$ 182 suggests surface erosion (Parker et al., 1972). The values of some of the previous 19 experimental work for the calculation of floc strength co-efficient $(\log C)$ and 20 constant $(\gamma)$ obtained for a variety of flocs are shown in Table 3. Good linearity is 21 always seen between floc size and shear rate on a log-log scale for all of the 22 experimental studies shown in the table. For example, both Bache et al. (1999) and 23 Biggs and Lant (2000) had an $\mathrm{R}^{2}$ correlation co-efficient in excess of 0.99. 
2 For a fixed shear rate the larger the value of $\log C$ the stronger the floc (Bache, 2004).

3 As has been explained, comparing values of $\log C$ between studies is not possible due

4 to the different impeller/tank geometries and different floc sizing protocols employed,

5 however a number of trends can be seen from within individual research. Wu et al.

6 (2003) saw that an increase in the polymer dose lead to an increase in the floc

7 strength coefficient for alum sludge flocs. A comparison of ferric hydroxide flocs in

8 tap water and sewage sludge showed an increase in $\log C$ from 1.5 to 1.9 with the

9 authors stating that floc strength was higher in tap water than sewage (Leentvaar and

10 Rebhun, 1983). For sewage flocs, it has been shown that adding polymeric flocculant

11 doubled the floc strength co-efficient. Bache et al., (1999) and Bache and Rasool

12 (2001) have investigated alumino-humic flocs. In the latter case, a useful comparison

13 of flocs obtained from flocculators at 7 water treatment plants treating water of high

14 colour (50-140 Hazen) has been made. The value of $\log C$ was highest for flocs

15 where polymer was used and in the instance of water that was initially of high 16 alkalinity.

Floc strength constant

19 Whilst the value of $\log C$ provides a good indication of how strong flocs are when 20 they are formed at a given shear rate, it does not provide information on how flocs 21 will respond to subsequent increases in shear rate. This information can be provided 22 by the previously mentioned floc strength factor but also by the floc strength constant $23(\gamma)$. The higher the value of $\gamma$ the more prone the flocs are to breakage into smaller 24 sizes with increasing shear rate. 
1 For alumino-humic flocs under low alkalinity conditions, the value of the slope varied

2 between 0.44 and 0.64 (Bache and Rasool, 2001). Looking at the data for comparable

3 Al doses (2.4-2.7 $\left.\mathrm{mg} \mathrm{L}^{-1}\right)$, the humic floc degradation was reduced from 0.63 to 0.44

4 when polymer aid had been added. The value of $\gamma$ was seen to increase when the

5 water alkalinity was high suggesting that these flocs were less able to withstand

6 increases in shear rate than the low alkalinity flocs. Coagulant dose also has an

7 impact on $\gamma$, for kaolin flocs, increasing coagulant dose from 4.02 to $5.02 \mathrm{mg} \mathrm{L}^{-1} \mathrm{Al}$

8 increased the floc strength constant, whilst above this coagulant dose there was a

9 decrease in $\gamma$ (Francois, 1987). This suggests that there is an optimum coagulant dose

10 in terms of floc strength.

12 For all types of floc the values of $\gamma$ were around 0.5 (the exception being alumino-

13 humic flocs formed in high alkalinity water were $\gamma=0.81$ ). Whilst these values of $\gamma$

14 do not highlight major differences in degradation rate for different types of floc (e.g.

15 sewage, kaolin and humic), the mode of breakage can be theoretically determined

16 from the floc strength constant. If it is assumed that viscous effects are responsible for

17 most of the energy dissipation in flocculating systems and the models of floc

18 breakage are correct, then it appears that floc breakage is generally dominated by floc

19 fragmentation as the value of $\gamma$ remains around the theoretical value of 0.5 as derived

20 by Parker et al. (1972). However, this strict theoretical interpretation is open to

21 debate. For example fragmentation and erosion could occur simultaneously in a

22 containing vessel. This may explain the result seen for the high alkalinity water, were

23 the value of $\gamma$ was half way between the theoretical values for fragmentation and

24 surface erosion. In addition, large flocs in an aggregated system may be larger than

25 the microscale $(\eta)$ whilst the smaller flocs may be smaller than $\eta$. This has been 
1 shown experimentally for activated sludge flocs with the $d_{95}>\eta>d_{50}$. This again

2 suggests that erosion and fragmentation can occur at the same time, perhaps as a

3 result of the larger flocs in the system fragmenting and the smaller flocs eroding

4 (Biggs and Lant, 2000).

6 Hydrodynamic shear based techniques using impellers have been widely used 7 because of their similarity to operational flocculators and the likelihood that 8 hydrodynamic shear stress is probably of great importance when considering floc 9 breakage. In addition these techniques have highlighted differences in how a floc will 10 respond to different increased levels of shear rate as determined by the value of $\gamma$. 11 However, whilst the observation of an empirical relationship between shear rate and

12 floc size is widespread, the problem has been in the interpretation and application of 13 shear based models to the data. Whilst experimental work is fitted to these models 14 there is little direct evidence to suggest either erosion or fragmentation is definitively 15 taking place. Ideally, the particle size distribution of a 'fragmenting' floc system needs to be compared to an 'eroding' system to show the differences in particle sizes to confirm that the models are totally accurate. A final problem with these techniques

18 has been an accurate description of the shear energy dissipated into impeller systems. $19 G_{a v}$ is probably not sufficient enough whilst critical threshold values of $G_{\max }$ have not 20 been sufficiently well modelled to directly relate to the resulting floc size. This has 21 lead to a number of workers tackling this problem by applying a reliable, accurate and 22 controllable measure of the energy input and the following section will review a 23 number of these techniques in turn. 
2 The use of ultrasound to condition sludge is a well known technique (Chu et al.,

3 2001). By applying a controlled ultrasonic field to a sludge suspension, flocs may be

4 effectively 'exploded' into smaller parts to improve biodegradability. During

5 ultrasonic treatment, pressure waves pass through a medium releasing large quantities

6 of energy. This induces the formation and collapse of gas bubbles. The result is a

7 release of energy in the form of temperature and turbulent eddies around the

8 collapsing bubble. There has been some limited application of this in determining floc

9 strength. Wen and Lee (1998) have developed a complex term for the calculation of a

10 floc strength value from an applied ultrasonic field (see Table 1). Above a critical

11 ultrasonic energy input it has been seen that kaolin flocs and activated sludge flocs

12 break-up and decrease in size (Wen and Lee, 1998; Chu et al., 2001). A direct

13 measure of the ultrasonic energy per unit volume of sample can be made that reflects

14 the flocs internal binding strength as the flocs break up. The resulting floc size can

15 then be measured and compared to the original floc size using one of the previously

16 mentioned techniques. For activated sludge thickened with alum, the effect of

17 polymer addition on floc strength has been investigated (Lee and Liu, 2001). A non-

18 ionic polymer was compared with a cationic polymer and it was seen that floc

19 strength decreased with increasing polymer dose and that non-ionic polymer showed

20 greater floc strength than cationic polymer. The major problem associated with this

21 technique is the impact of temperature. At an applied ultrasonic rate of $44 \mathrm{Watts}^{-1}$

22 the temperature was seen to increase from 20 to $56^{\circ} \mathrm{C}$ in just over 1 minute.

23 Therefore considerable temperature control needs to be applied in order to better

24 stabilise the system conditions. 
1 Wen and Lee (1998) investigated the strength of clay coagulated with cationic

2 polymer for different $\mathrm{pH}$ and polymer dose. They found that at higher $\mathrm{pH}$ and

3 polymer dose, the initial floc size was larger. The results were contradictory in that

4 the large flocs formed at $\mathrm{pH} 7$ and 10 were observed to break down at a faster rate

5 than at $\mathrm{pH} 3$ in terms of floc size. However, the binding strength based on Equation 4

6 was observed to increase with both polymer and $\mathrm{pH}$. This is perhaps a reflection of

7 there being two approaches of considering floc strength. The first is a measure of the

8 maximum floc size attained at the end of the floc formation process such that larger

9 flocs should be considered stronger than smaller flocs because they have reached a

10 bigger size. The second considers the floc strength as a measure of the strength of floc

11 bonds to withstand increases in energy once formed.

13 For activated sludge flocs the use of ultrasound is confused due to the effect of

14 ultrasound on bacterial components of the floc. Ultrasound increases the formation of

15 free radicals which can impact on bacterial metabolism and also cause cell lysis

16 (Jorand et al., 1995). Therefore, in these instances the applied energy may be causing

17 other effects other than breaking apart primary particles within the floc.For water

18 treatment flocs that are generally dominated by non-living chemical constituents,

19 ultrasonic methods may have potential for determining the forces required to break

20 flocs. From an operational sense it is difficult to relate the energy experienced by

21 flocs from an ultrasonic field to the hydrodynamic shear conditions that are important

22 in a flocculator. However, as inter-particle bonds are being broken in both techniques

23 a comparison of the results between the different methods would be of great interest. 
2 Bache and Al-Ani (1989) developed a technique whereby flocs are exposed to stress

3 in a vibrating settling column. An oscillating plunger was used to provide turbulent

4 energy dissipation in the column. In this manner relatively uniform energy dissipation

5 can be achieved in the horizontal plane with shear stress increasing as flocs pass

6 down the column, therefore the height at which a floc ruptures in the column is

7 proportional to a certain level of energy dissipation. A floc breaks when it passes

8 through a region where the hydrodynamic forces are greater than the binding force at

9 the point of rupture within the floc. The advantage of such a system is that the

10 hydrodynamic shear stress at each point in the column may be more accurately

11 modelled when compared to the more complex flow of impeller systems. In this

12 technique floc size before and after breakage has been monitored using closed circuit

13 television (CCTV) and image analysis. The underlying trend emerging from this

14 technique is for large flocs to rupture higher in the column than smaller floc

15 aggregates, showing the increased susceptibility of large flocs to increases in shear

16 rate. This has been shown for kaolin-alum flocs (Bache and Al-Ani, 1989) and for

17 humic-alum flocs (Bache et al., 1991). The calculation of a value for floc strength

18 from these data is shown in Equation 5 (Table 1). This has been derived from a force

19 balance between accelerations across the floc at the plane of rupture where turbulent

20 energy acceleration have been defined as $\sqrt{3} \varepsilon^{3 / 4} v^{-1 / 4}$ from Levich (1962):

$21 \frac{1}{4} \pi d^{2} \sigma=2 \frac{\pi}{6} \rho_{w} d^{3} \sqrt{3} \frac{\varepsilon^{3 / 4}}{v^{1 / 4}} \quad$ Equation 14

$22 d$ is the size of floc sub-units $(\mathrm{m}), \sigma$ is the floc strength per unit area $\left(\mathrm{N} \mathrm{m}^{-2}\right), \rho_{w}$ is the density of water

$23\left(\mathrm{~kg} \mathrm{~m}^{-3}\right), v$ is the kinematic viscosity $\left(\mathrm{m} \mathrm{s}^{-1}\right)$ and $\varepsilon$ the energy dissipation $\left(\mathrm{N} \mathrm{m} \mathrm{s}^{-1} \mathrm{~kg}^{-1}\right)$. 
1 Floc strength calculations have shown that flocs sheared at high $G_{a v}$ values were

2 smaller but had higher strength. For example, flocs sheared at $50 \mathrm{~s}^{-1}$ had a $d_{95}$ of 238

$3 \mu \mathrm{m}$ and a strength of $0.08 \mathrm{~N} \mathrm{~m}^{-2}$, whilst flocs sheared at $230 \mathrm{~s}^{-1}$ had a $d_{95}$ of $120 \mu \mathrm{m}$

4 and a strength of $0.42 \mathrm{~N} \mathrm{~m}^{-2}$. The relative floc strength of alumino-humic flocs was

5 found to change with coagulant dose. For doses of between $2-7 \mathrm{mg} \mathrm{L}^{-1} \mathrm{Al}$, an

6 optimum was seen at $4 \mathrm{mg} \mathrm{L}^{-1}$.

\subsection{Microscopic Floc Strength Tests}

9 Whilst macroscopic techniques rely upon complex theory of turbulence, eddy size and floc breakage models, recent work has been carried out to gain a more direct

11 measurement of floc strength by taking individual flocs and finding the force required to pull or compress a floc until breakage (Yeung and Pelton, 1996 and Zhang et al.,

13 1999). The principal advantage of such a technique being that an understanding of the

14 mechanisms of how and where flocs break may be gleaned and a floc rupture force 15 may be directly measured to give floc strength. This may eventually lead to a more thorough knowledge of the currently poorly-understood mechanisms of floc breakage.

17 The following section briefly reviews two microscopic techniques.

\subsubsection{Micromechanical approach}

20 In this method, floc strength is measured by the tensile force required to break single

21 flocs (Yeung and Pelton, 1996; Yeung et al., 1997). A schematic overview of this technique can be seen in Figure 4. Calcium carbonate flocs coagulated in $\mathrm{NaCl}$ with

23 polymeric floc aid were placed in a sample chamber consisting of two glass cover 24 slips separated by $2 \mathrm{~mm}$. The force required to rupture the flocs was determined by 25 carefully attaching single flocs onto a glass rod cantilever beam and attaching and 
1 translating an opposing pipette horizontally until the floc broke. The deflection of the

2 cantilever may be directly converted into a floc rupture force, provided the cantilever

3 stiffness is known, using sensitive micromanipulators. Floc size before and after

4 breakage was determined by averaging the major and minor axis of the aggregates of

5 the original floc and the broken floc pieces. In their first study (Yeung and Pelton,

6 1996) floc strength was reported as simply the force required to break apart the floc.

7 Initial floc sizes ranged from between 5-50 $\mu \mathrm{m}$ diameter. In this instance when this

8 force is plotted against floc size no correlation was seen between floc strength and

9 size. A change in floc strength was seen when two polymeric flocculants were 10 compared with the first system having an average floc strength of $64 \mathrm{nN}$ and the 11 second was $110 \mathrm{nN}$. Boller and Blaser (1998) have transformed these data into a floc 12 rupture pressure so that floc strength is found from the ratio of the rupture force to the 13 cross sectional area of the smaller fractured aggregate (as shown in Equation 6 in 14 Table 1) giving floc strengths in the region of 100-1000 $\mathrm{N} \mathrm{m}^{-2}$. In this way, the size 15 dependency of floc strength was again seen, such that smaller flocs showed increased 16 strength. The application of this technique has been taken further to show the effect of 17 mixing speed on floc strength (Yeung et al., 1997). A range of mixing speeds 18 between 50-2500 rpm were investigated for paper pulp with calcium carbonate 19 flocculated with polymeric flocculant. An optimum mixing speed was determined at $20500 \mathrm{rpm}$ that gave optimum floc strength of $1,500 \mathrm{~N} \mathrm{~m}^{-2}$. However, it should be 21 stressed that the sampling technique may lead to significant floc breakage or 22 aggregation, such that the original floc size, and therefore strength, may not be 23 measured. 
1 The technique provides an interesting insight into floc breakage in the tensile mode. It

2 was observed that not all flocs breakages resulted in large scale fragmentation. This

3 contradicts hydrodynamic shear models that suggest tensile stress is responsible for

4 large scale fragmentation. It was hypothesised that flocs were breaking at their

5 narrowest point because it is here that there are fewer attachment sites. The size ratio

6 of floc fragments $\left(d_{1}\right)$ after breakage with the initial floc $\left(d_{0}\right)$ were compared with floc

7 compaction (as determined by fractal dimension analysis). Values of $d_{1} / d_{0}$

8 approaching 0.5 indicate that the floc has been split into two similar sized pieces

9 whilst near 0 and 1 a floc has been broken into a very small and large aggregate. The

10 authors argue that the mode of floc breakage is therefore more to do with floc

11 compaction than the differences in turbulence stresses and eddy size. Very compact

12 flocs have fewer bonds in their margins, so surface erosion is more likely to occur.

13 More loosely bound flocs are more likely to have weak points randomly located

14 anywhere across their cross-section and are therefore more susceptible to large scale

15 fragmentation. This questions one of the fundamental assumptions of the shear based

16 floc strength characterisations based upon Equation 12 that flocs are homogenous 17 structures composed of similar primary particle units.

19 The micromechanical technique has provided a useful addition to the field of floc 20 strength quantification. However, as yet the application has been limited to the 21 measurement of only a few hundred individual floc aggregates in total and across a 22 relatively narrow range of floc types. More work is required in this field in order to 23 assess its broad application to all types of floc. In addition, the importance of tensile 24 stress as a mechanism for floc breakage in flocculators and other WTW processes has 25 yet to have been fully quantified. 
2 A further microscopic technique has measured the compression force required to

3 break flocs between a glass slide and a fibre optic probe (Zhang et al., 1999). In this

4 technique, a sample of floc suspension was placed on a microscope slide, individual

5 flocs could then be selected using a microscope (Figure 5). A $50 \mu \mathrm{m}$ probe with one

6 flattened end was mounted onto a force transducer and lowered just above a floc

7 aggregate using a micromanipulator. The transducer then lowered the probe at a set

8 speed until the aggregate broke from compression between the probe and slide. The

9 applied force was then measured as the breaking force (Equation 7). The flocs under

10 investigation were very small latex particles aggregated in a salt solution. The mean

11 size of flocs aggregated by vortexing was $2.5 \mu \mathrm{m}$ and the mean floc strength was 5.3

$12 \mu \mathrm{N}$. However, the experimental procedure did not measure the sizes of the residual

13 flocs once they had been broken. This meant the results could not be normalised to a

14 floc rupture force over the floc cross sectional area and so compared to the other 15 techniques. This method provides an alternative microscopic measure of floc size and 16 again needs to be assessed over a range of floc types in order to rigorously evaluate 17 the technique. However from an operational sense it is difficult to think of a situation 18 where flocs would be exposed to such a compression stress under normal solid/liquid 19 separation conditions and as such this value of floc strength may not be indicative of 20 the likelihood of floc breakage in industrial unit processes.

\section{4. Comparison of floc strength values}

23 Direct comparison of floc strength between the different techniques is made difficult

24 because each technique measures floc strength in a different way giving either floc 25 strength as a relative measure or an actual breakage force. However an attempt has 
1 been made in Table 4 to highlight the general trends that the floc strength

2 measurements indicate. Table 5 emphasises some of these trends with a comparison

3 of absolute values of floc strength from a number of techniques were the force per

4 area of floc has been measured.

6 The most significant trend to emerge from these strength tests is the increase in floc 7 strength with a decrease in floc size. This can be clearly seen from data in Table 5 for

8 alumino-humic flocs with an increased floc strength of over five times with a halving

9 of the initial floc size. This is further supported by polymer-calcium carbonate flocs.

10 Polymer A produced flocs with an average diameter of $25 \mu \mathrm{m}$ and an average floc

11 strength of $100 \mathrm{~N} \mathrm{~m}^{-2}$, whilst polymer B produced smaller flocs of $10 \mu \mathrm{m}$ with an 12 increase in average floc strength to $1000 \mathrm{~N} \mathrm{~m}^{-2}$. A mechanistic explanation for this 13 relationship has not yet been fully described. However, the reasons are likely to relate 14 to floc compaction and the number of internal bonds. In much of the strength work, 15 flocs are grown and then exposed to an increased shear rate. This acts to break flocs 16 and therefore reduce the average floc size in the suspension. The breakage procedure 17 breaks flocs at their weakest points, which results in smaller pieces that are smaller 18 and more compact. This has been shown by fractal dimension analysis of 19 polystyrene-alum flocs. There is a large amount of evidence suggesting that flocs are 20 examples of fractal structures (Gregory, 1998, Gorczyca and Ganczarczyk, 1999, 21 Thomas et al., 1999; Bushell et al., 2002). The floc fractal dimension $\left(D_{f}\right)$ can 22 indicate the openness of the internal floc structure with a higher fractal dimension 23 indicating a more compact structure. Flocs formed at a high shear rate $\left(G_{a v}=300 \mathrm{~s}^{-1}\right)$ 24 were small and had a fractal dimension of 2.65 whilst floc size increased and the 25 fractal dimension was reduced to 2.4 when the flocs were formed at a much lower 
1 shear rate $\left(G_{a v}=50 \mathrm{~s}^{-1}\right)$ (Spicer et al., 1998). More compact structures indicate that

2 primary particles may have more attachments with one another or repulsive forces

3 between these particles is at a minimum. Floc restructuring during breakage is one

4 mechanism for allowing primary particles to become closer to one another so that floc

5 internal bonds break and re-form at more favourable points within the floc where the

6 attractive force is greater or the repulsive force lower.

8 Similarly, compaction is thought to explain why an optimum coagulant dose exists in 9 terms of floc strength. For charge neutralisation coagulation mechanisms, the 10 optimum floc characteristics should be seen when the repulsion forces between 11 primary particles are low. However, a slight amount of charge repulsion allows 12 attached particles to re-arrange into more compact structures rather than attaching at 13 the first contact (Waite et al., 2001). In water and wastewater operations, charge 14 neutralisation is generally achieved by the addition of charged metal ions of an 15 opposite charge. Increasing or decreasing the ratio of the charged coagulant will 16 therefore reduces or increases the balance of the charge within the floc above or 17 below an optimum (Bache et al., 1991).

19 A generally held conception within the water and wastewater industry is that the 20 addition of polymer acts to increase floc structural characteristics by aiming to 21 increase floc size, strength, settleability and filterability (Bratby, 1980). From the 22 limited data presented in this review, this statement appears to be at least partially 23 true in terms of floc strength and size. Sewage flocs and alumino-humic flocs were 24 seen to increase in size with the addition of a polymeric floc aid. However, only the 25 alumino-humic flocs showed improved resistance to shear rates, implying an increase 
1 in floc strength. The difference in floc strength with and without polymer is likely to

2 be some reflection of the binding mechanisms of the polymer to the primary particles

3 of the floc. For a range of polymers (anionic, cationic and non-ionic), floc strength

4 was seen to decline for biological flocs in their response to increases in shear rate

5 (Lee and Liu, 2001; Leentvaar and Rebhun, 1983). No mechanistic explanations were

6 given although one possible hypothesis was a toxicity effect from the polymer on the

7 biological component of the floc. The polymer may act to kill bacteria or prevent

8 bacterial adhesion mechanisms within the floc, thus reducing the overall bonding

9 capacity in the floc through changes in concentration and character or extracellular

10 polymeric substances. However, some of this previous research goes against intuitive

11 and practical experience of polymers used in water and wastewater treatment. Much

12 more work is required in this field to more adequately quantify the effects of

13 polymeric flocculants.

15 During the removal of solid particles, enmeshment and bridging of particles within 16 the precipitated coagulant matrix are thought to be the principal binding forces 17 holding the floc together. These types of bond are considered much stronger than van 18 der Waals attractive forces formed during charge neutralisation (Bache et al., 1997).

19 This is supported by the experimental data shown in Table 5. From the available data, 20 there are considerable differences in floc strength for different types of aggregate.

21 Flocs composed of coagulant and particles were one to two orders of magnitude 22 stronger than charge neutralisation flocs.

24 Flocs formed from waters of high colour and high natural organic matter (NOM) 25 content are widely recognised as being fragile structures when compared to other 
1 flocs (Bache et al., 1997). The floc strength data available confirm this, with these

2 flocs being weaker than flocs formed by charge neutralisation at their isoelectric point

3 (IEP). The weakness of humic flocs is explained by Bache et al. (1999) to be due to

4 the fact that charge neutralisation is the main removal route NOM removal preventing

5 stronger bridging bonds from forming. This in part explains the weakness of organic

6 flocs but does not help explain why IEP flocs are considerably stronger than humic

7 flocs. If both flocs are formed by charge neutralisation, then van der Waals forces

8 between primary particles will dominate. The reduced floc strength of humic flocs

9 therefore suggests an increased degree of repulsion within the floc matrix. This makes

10 sense because organic matter is a complex mixture of different organic compounds

11 (Goslan et al., 2002). These organic molecules have differing degrees of charge and 12 hydrophobicity (O’Melia et al., 1999). Therefore, whilst some molecules and parts of 13 molecules may be effectively charge neutralised by coagulants, regions of similarly 14 charge will exist that increase repulsion within the floc.

\section{5. Conclusions}

17 There have been a number of different approaches taken in measuring floc strength.

18 Some workers consider that floc strength is indicated by the size a floc reaches at the 19 end of its growth phase, whilst others consider the force required to break already 20 formed flocs.

22 Most research has concentrated on exposing flocs to increased shear rate in a 23 containing vessel by the application of stirring, ultrasonification and oscillation. More 24 recently microscopic techniques have been developed that relate the energy required 25 to pull apart or compress individual flocs until breakage. 
1 Whilst there is strong evidence showing an empirical relationship between the applied

2 shear rate and the final floc size distribution, there are a number of problems

3 associated with comparing the data from one study to another. The interpretations of

4 floc breakage models need to be further analysed. These models ascribe floc breakage

5 as either erosion or fragmentation based upon the rate of floc breakage with

6 increasing shear rate relative to the eddy size in the system. These interpretations are

7 open to debate given the incomplete understanding of how eddies interact with flocs

8 during floc breakage. Different impeller geometries and containing vessels give rise

9 to different shear patterns and maximum shear levels experienced by flocs that result

10 in different floc breakage behaviour. For this reason a simple consideration of how

11 floc size changes relative to its initial size may give the best global indication of how 12 strong flocs are.

14 Some general trends have emerged from floc strength tests that show that floc 15 strength increases with decreasing floc size. The addition of polymer decreased floc 16 strength for biological flocs and increased floc strength for chemical flocs.

18 Floc strength is a difficult parameter to measure accurately due to the inherent 19 fragility and complexity of floc structures. As yet, there is no detailed understanding 20 of the internal composition and bonding that occurs within a floc aggregate such as 21 the number of bonds, locations of points of attachment and internal attractive and 22 repulsive forces within the structure. Therefore many of the floc strength and 23 breakage models developed so far have not reached a thorough mechanistic level. 
2 Amirtharajah, A. and O'Melia, C.R. (1990) Coagulation Processes: Destabilisation, 3 Mixing and Flocculation. In: American Water Works Association Water Quality and

4 Treatment A Handbook of Community Water Supplies. McGraw-Hill, New York.

6 Bache, D. H. (2004) Floc Rupture and Turbulence: a Framework for Analysis.

$7 \quad$ Chemical Engineering Science 59 2521-2534.

9 Bache, D. H. and Rasool, E.R. (2001) Characteristics of Alumino-Humic Flocs in 10 Relation to DAF Performance. Water Science and Technology 43 (8), 203-208.

12 Bache, D. H., Johnson, C., McGilligan, J.F., and Rasool, E. (1997) A Conceptual 13 View of Floc Structure in the Sweep Floc Domain. Water Science and Technology 36 $14(4), 49-56$.

16 Bache, D. H., Rasool, E., Moffatt, D., and McGilligan, F.J. (1999) On the Strength 17 and Character of Alumino-Humic Flocs. Water Science and Technology 40 (9), 811888.

20 Bache, D. H., Hossain, M.D., Al-Ani, S.H. and Jackson, P.J. (1991) Optimum 21 Coagulation Conditions for a Coloured Water in Terms of Floc Size, Density and 22 Strength. Water Supply 9, 93-102.

24 Bache, D. H. and Al-Ani, S.H. (1989) Development of a System for Evaluating Floc 25 Strength. Water Science and Technology 21, 529-537. 
1 Biggs, C. A. and Lant, P. A. (2000) Activated Sludge Flocculation: On-Line

2 Determination of Floc Size and the Effect of Shear. Water Research 34, 2542-2550.

3

4 Boller, M. and Blaser, S. (1998) Particles Under Stress. Water Science and

$5 \quad$ Technology 37 (10), 9-29.

6

7 Bouyer, D., Line, A., Cockx, A., and Do-Quang, Z. (2001) Experimental Analysis of

8 Floc Size Distribution and Hydrodynamics in a Jar-test. Transactions of the Institute

9 of Chemical Engineers 79 (A), 1017-1024.

10

11 Brakalov, L. B. (1987) A Connection between the Orthokinetic Coagulation Capture

12 Efficiency of Aggregates and their Maximum Size. Chemical Engineering Science

$13 \quad 422373-2383$

14

15 Bratby, J. (1980) Coagulation and Flocculation. Uplands Press Ltd, Croydon, UK, pp $16 \quad 55-89$.

17

18 Burgess, M. S., Phipps, J. S. and Xiao, H. (2000) Flocculation of PCC Induced by 19 Polymer/Microparticle Systems: Floc Characteristics. Nordic Pulp and Paper $20 \quad$ Research 15 (5), 2000.

21

22 Bushell, G. C., Yan, Y. D., Woodfield, D., Raper, J., and Amal, R. (2002) On

23 Techniques for the Measurement of the Mass Fractal Dimension of Aggregates.

24 Advances in Colloid and Interface Science 95, 1-50. 
1 Camp T.R. and Stein P.C. (1943) Velocity Gradients and Internal Work in Fluid

2 Motion. Journal of the Boston Society of Civil Engineers 30 219-237.

3

4 Chakraborti, R. K., Atkinson, J. F. and Van Benschoten, J. E. (2003) Characterisation

5 of Alum Floc by Image Processing. Environmental Science and Technology 34 (18),

$6 \quad 3969-3979$.

7

8 Chu, C. P., Chang, B. V., Liao, G. S., Jean, D. S., and Lee, D. J. (2001) Observations

9 on Changes in Ultrasonically Treated Waste-Activated Sludge. Water Research $10 \quad 35,1038-1046$.

11

12 Cornwell, D. A. and Bishop, M. M. (1983) Determining Velocity Gradients in

13 Laboratory and Full Scale Systems. Journal of the American Water Works $14 \quad$ Association 75 (9), 470-475.

15

16 Ducoste, J. J. and Clarke, M. M (1998) The Influence of Tank Size and Impeller 17 Geometry on Turbulent Flocculation: I. Experimental. Environmental Engineering $18 \quad$ Science 15 (3), 215-224.

20 Farrow, J. and Warren, L. (1993) Measurement of the Size of Aggregates in 21 Suspension. In: Coagulation and Flocculation - Theory and Applications, pp. 39122 426, New York.

24 Fitzpatrick, S. B., Fradin, E. and Gregory, J. (2003) Temperature Effects on 25 Flocculation Using Different Coagulants. In: Proceedings of the Nano and Micro 
1 Particles in Water and Wastewater Treatment Conference; International Water

2 Association: Zurich, September 2003.

3

4 Francois, R. J. (1987) Strength of Aluminium Hydroxide Flocs. Water Research 21, $5 \quad 1023-1030$.

6

7 Gorczyca, B. and Ganczarczyk, J. (1999). Structure and Porosity of Alum

8 Coagulation Flocs. Water Quality Research Journal of Canada 34, 653-666.

9

10 Goslan, E. H., Fearing, D. A., Banks, J., Wilson, D., Hillis, P., Campbell, A.T., and

11 Parsons, S. A. (2002) Seasonal Variations in the Disinfection By-product Precursor 12 Profile of a Reservoir Water. Journal of Water Supply: Research and Technology $13 \quad$ AQUA 51 475-482.

15 Govoreanu, R., Seghers, D., Nopens, I., De Clercq, B., Saveyn, H., Capalozza, C., 16 Van der Meeren, P., Verstraete, W., Top, E. and Vanrolleghem, P.A. (2000) Linking 17 Floc Structure and Settling Properties to Activated Sludge Population Dynamics in an 18 SBR. Water Science and Technology 47 (12), 9-18.

20 Gregor, J. E., Nokes, C. J., and Fenton, E. (1997) Optimising Natural Organic Matter

21 Removal from Low Turbidity Waters by Controlled $\mathrm{pH}$ Adjustment of Aluminium 22 Coagulation. Water Research 31, 2949-2958.

24 Gregory, J. and Dupont, V. (2001) Properties of Flocs Produced by Water Treatment 25 Coagulants. Water Science and Technology 44, 231-236. 
1 Gregory, J. (1989) Fundamentals of Flocculation. Critical Reviews in Environmental

2 Control 19, 185-230.

3

4 Gregory, J. (1998) The Role of Floc Density in Solid-Liquid Separation. Filtration 5 and Separation 35, 367-371.

6

7 Gregory, J. (2003) Monitoring Floc Formation and Breakage In Proceedings of the 8 Nano and Micro Particles in Water and Wastewater Treatment Conference;

9 International Water Association: Zurich, September 2003.

11 Gregory, J. and Nelson, D. W. (1986) Monitoring of Aggregates in Flowing 12 Suspension. Colloids and Surfaces 18, 175-188.

14 Jorand, F., Zartarian, F, Thomas, F, Block, J. C., Bottero, J. Y., Villemin, G., Urbain, 15 V. and Manem, J. (1995) Chemical and Structural (2D) Linkage Between Bacteria 16 Within Activated Sludge Flocs. Water Research 29, 1639-1647.

18 Klimpel, R. C. and Hogg, R. (1991) Evaluation of Floc Structures. Colloids and 19 Surfaces 55, 279-288.

21 Lee, C. H. and Liu, J. C. (2001) Sludge Dewaterability and Floc Structure in Dual 22 Polymer Conditioning. Advances in Environmental Research 5, 129-136. 
1 Levich, V. G. (1962) Physico-Chemical Hydrodynamics. Prentice Hall, Englewood

2 Cliffs, US.

3

4 McCurdy, K., Carlson, K. and Gregory, D. (2004) Floc Morphology and Cyclic

5 Shearing Recovery: Comparison of Alum and Polyaluminium Chloride Coagulants.

$6 \quad$ Water Research 38, 486-494.

7

8 Mikkelsen, L. H. and Keiding, K. (2002) The Shear Sensitivity of Activated Sludge:

9 an Evaluation of the Possibility for a Standardised Floc Strength Test. Water $10 \quad$ Research 36, 2931-2940.

11

12 O’Melia, C. R., Becker, W. C. and Au, K. K. (1999) Removal of Humic Substances 13 by Coagulation. Water Science and Technology $\mathbf{4 0}$ (9), 47-54.

15 Parker, D. S., Kaufman, W. J., and Jenkins, D (1972) Floc Breakup in Turbulent 16 Flocculation Processes. Journal of the Sanitary Engineering Division: Proceedings of 17 the American Society of Civil Engineers SA 1 79-99.

19 Thomas, D. N., Judd, S. J., and Fawcett, N. (1999) Flocculation Modelling: A 20 Review. Water Research 33, 1579-1592.

21

22 Waite, T. D., Cleaver, J. K. and Beattie, J. K. (2001) Aggregation Kinetics and 23 Fractal Structure of $\gamma$-Alumina Assemblages. Colloid and Interface Science 241, 33324339. 
1 Wang, X. C., Jin, P. K. and Gregory, J. (2002) Structure of Al-Humic Flocs and their

2 Removal at Slightly Acidic and Neutral pH. Water Science and Technology: Water

$3 \quad$ Supply 2 (2), 99-106.

4

5 Wen, H. J. and Lee, D. J. (1998) Strength of Cationic Polymer-Flocculated Clay

6 Flocs. Advances in Environmental Research 2, 390-396.

7

8 Wu, C. C., Wu, J. J., and Huang, R. Y. (2003) Floc Strength and Dewatering

$9 \quad$ Efficiency of Alum Sludge. Advances in Environmental Research 7, 617-621.

11 Yeung, A. K., Gibbs, A., and Pelton, R. P. (1997) Effect of Shear on the Strength of 12 Polymer-Induced Flocs. Journal of Colloid and Interface Science 196, 113-115.

14 Yeung, A. K. C. and Pelton, R. (1996) Micromechanics: A New Approach to 15 Studying the Strength and Breakup of Flocs. Journal of Colloid and Interface Science $16 \mathbf{1 8 4}, 579-585$.

18 Yukselen, M. A. and Gregory, J. (2004) The Reversibility of Floc Breakage. 19 International Journal of Mineral Processing 73, 251-259.

21 Zhang, Z., Sisk, M. L., Mashmoushy, H., and Thomas, C. R. (1999) Characterisation 22 of the Breaking Force of Latex Particle Aggregates by Micromanipulation. Particle 23 Particle System Characterisation 16, 278-283. 
1) Large Scale Fragmentation

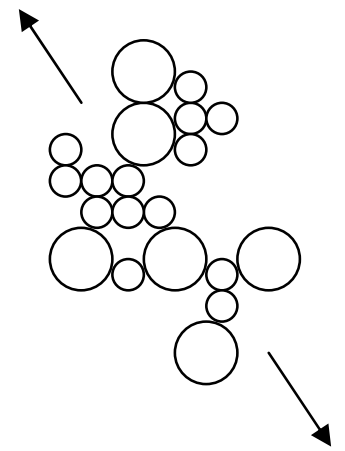

2) Surface Erosion

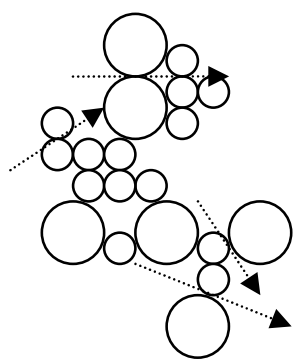

Tensile stress

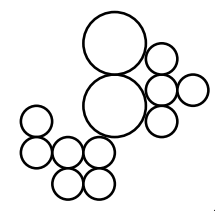<smiles></smiles>

Shear stress

$\bigcirc$

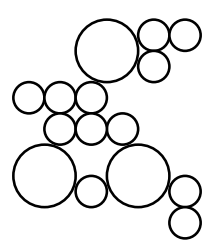

0

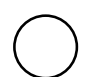

5 Figure 1. Two proposed mechanisms for the breakage of flocs under different shear 6 conditions. 


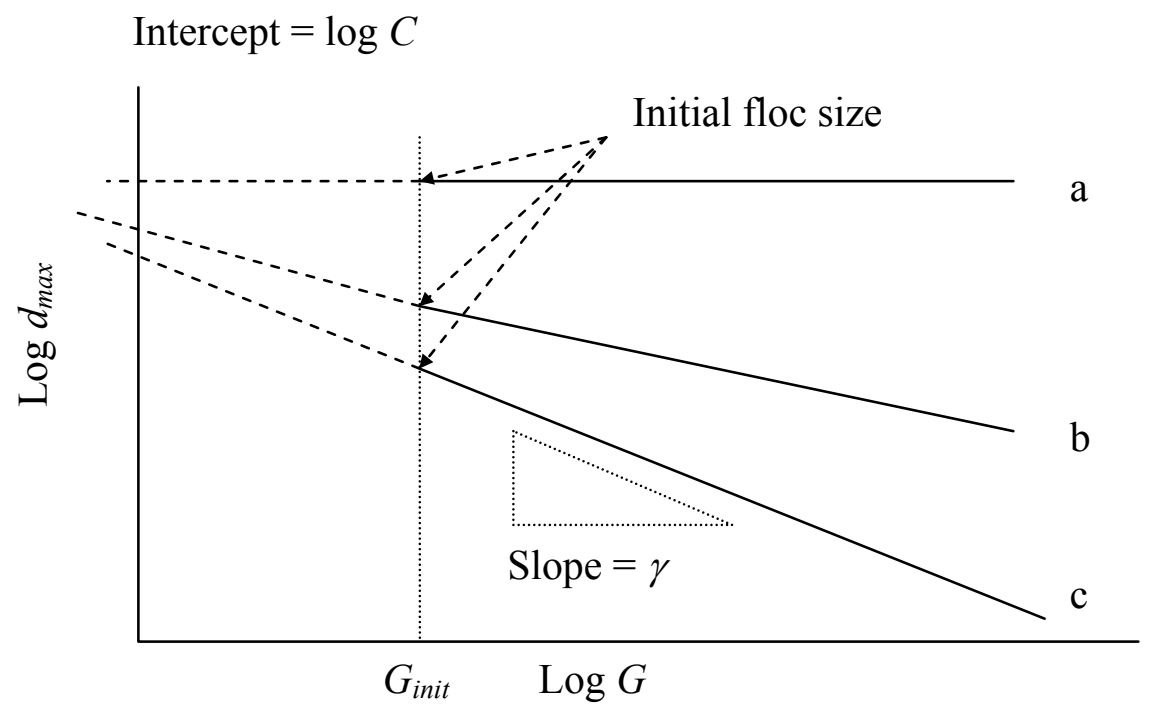

1

2 Figure 2. The relationship between the change in particle size and an increase in 3 velocity gradient for 3 types of floc. Floc (a) is resistant to breakage, floc (b) is 4 thought to break due to large scale fragmentation and floc (c) is thought to break by 5 surface erosion

6

7

8

9

10

11

12

13

14

15

16

17

18

19 


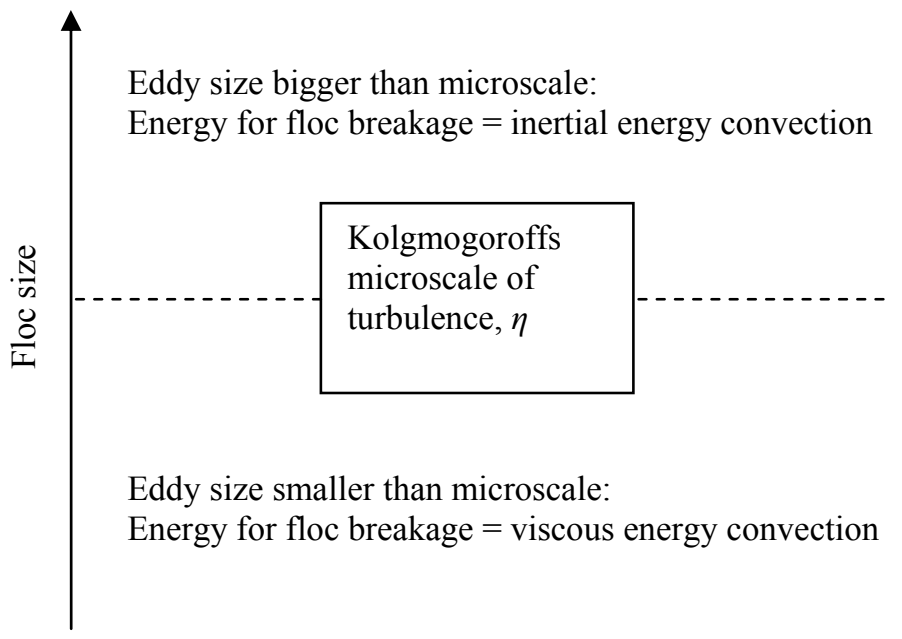

2 Figure 3. The importance of eddy size on floc break-up mechanism.

3

4

5

6

7

8

9

10

11

12

13

14

15

16

17

18

19

20

21

22 
Floc held between

two pipettes and two

glass cover slips

Micro-

manipulator

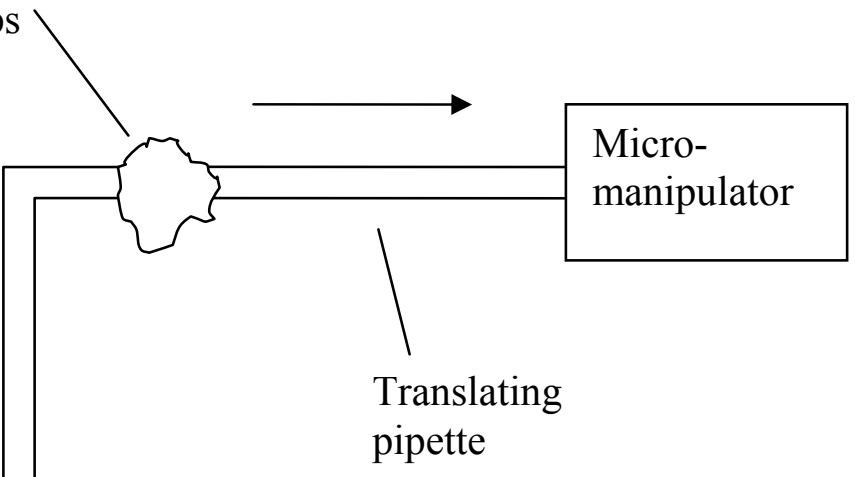

Pipette moved

until floc breakage

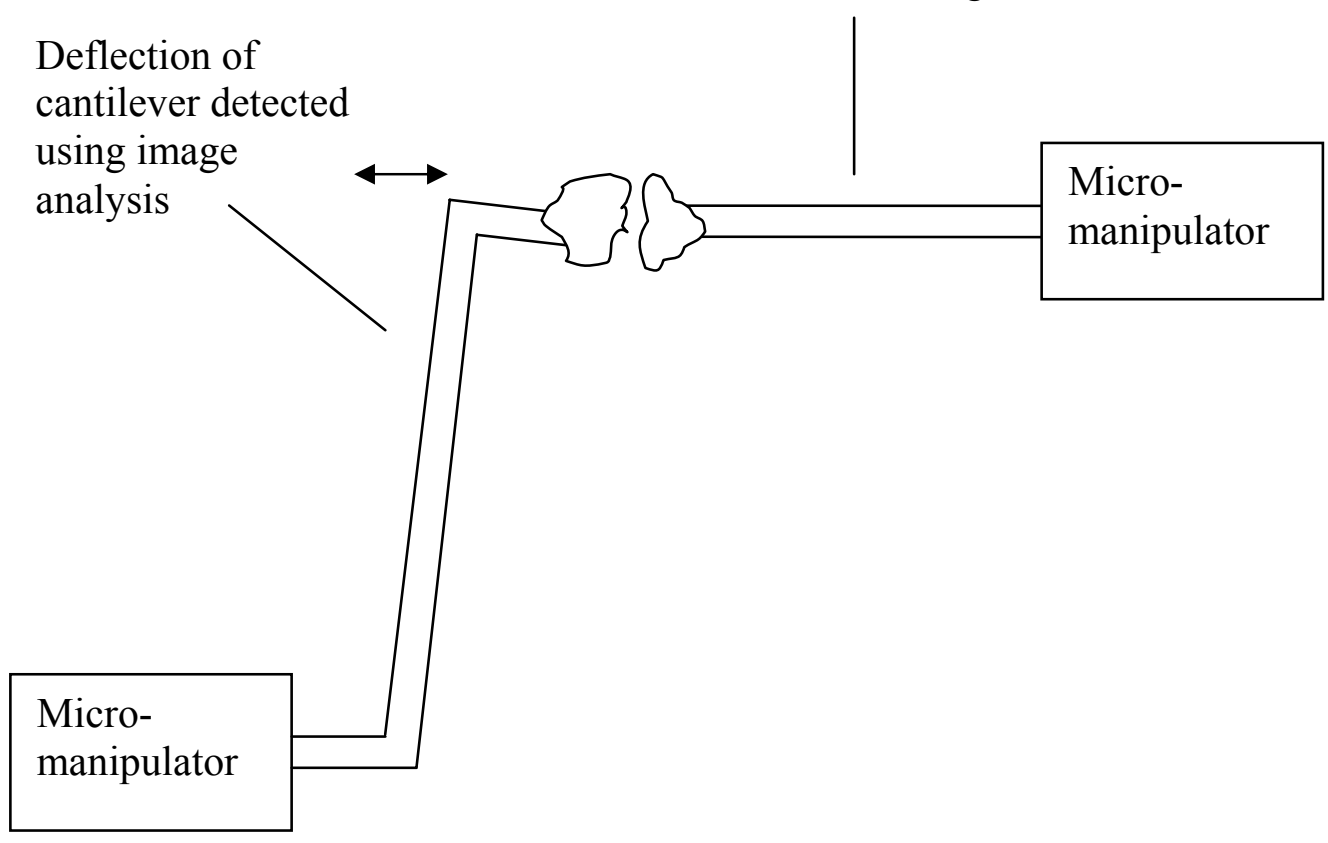

2 Figure 4. A schematic overview of the micromechanical floc strength technique.

3

4

5

6 


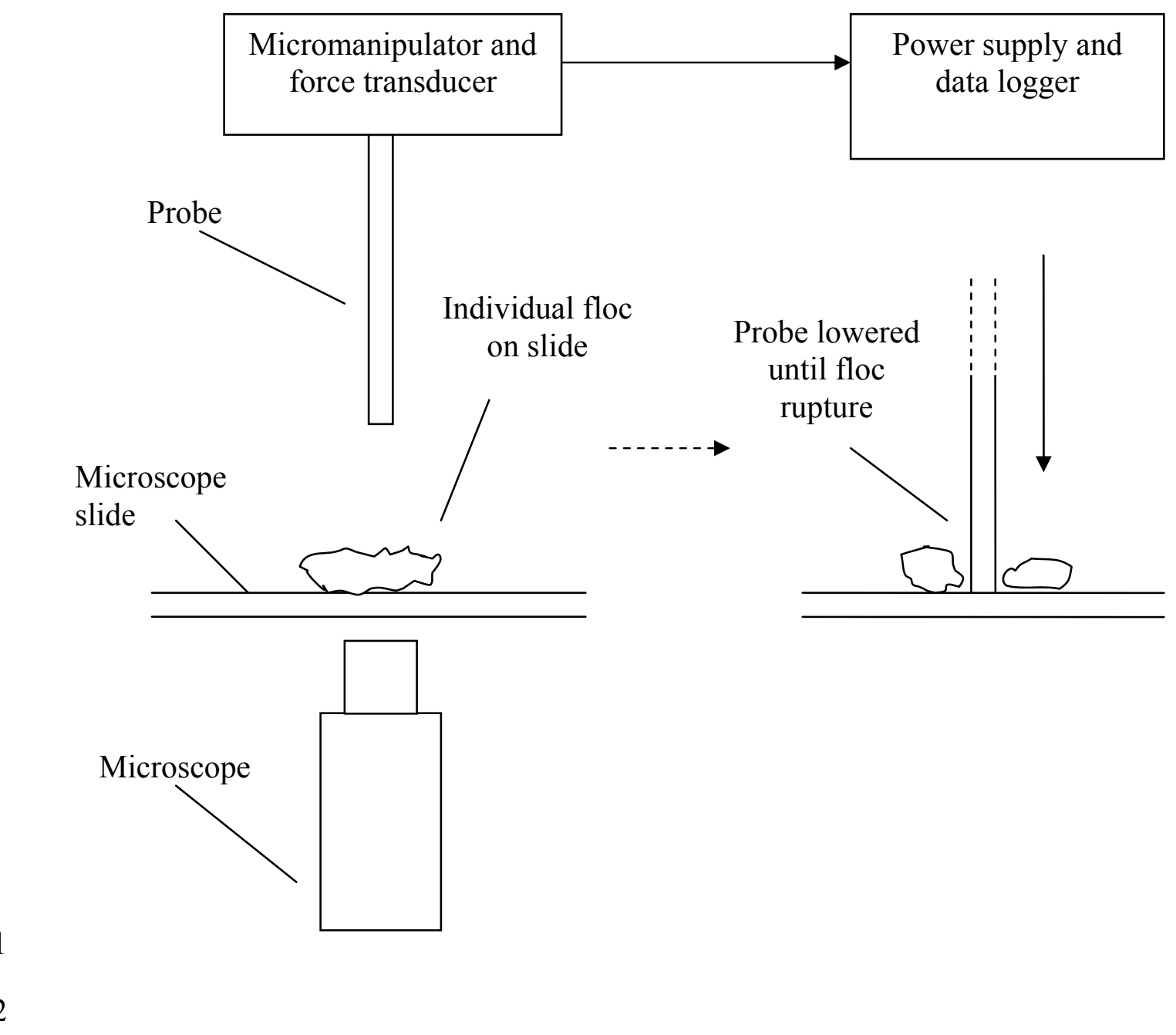

3 Figure 5. A schematic overview of the micromanipulation floc strength technique.

4

5

6

7

8

9

10

11

12

13 
2 Table 1. A review of the techniques used for determining floc strength.

\begin{tabular}{|c|c|c|c|}
\hline \multicolumn{2}{|c|}{ Strength technique } & \multirow{2}{*}{$\begin{array}{l}\text { Description } \\
\text { Exposure of floc to single level of increased shear within } \\
\text { a containing vessel and compare the ratio of the floc size } \\
\text { before and after breakage (Francois, 1987; Fitzpatrick et } \\
a l, 2003 \text { ) }\end{array}$} & Strength calculation \\
\hline $\begin{array}{l}\text { Macroscopi } \\
\text { c techniques }\end{array}$ & Impeller & & $\begin{array}{l}\text { Strength factor }=\frac{d(2)}{d(1)} \times 100 \quad \text { Equation } 2 \\
\text { where } d(1) \text { is the average floc size of the plateau before breakage }(\mathrm{m}) \text { and } d(2) \text { is the } \\
\text { floc size after the floc breakage period }(\mathrm{m})\end{array}$ \\
\hline & & $\begin{array}{l}\text { Exposure of the floc to increased levels of shear at a } \\
\text { controllable rate within a containing vessel and measure } \\
\text { the energy input for floc breakage (Leentvaar and } \\
\text { Rebhun, 1983; Francois, 1987). }\end{array}$ & $\begin{array}{l}\log d_{\text {max }}=\log C-\gamma \log G \quad \text { Equation } 3 \\
d_{\text {max }} \text { is the maximum floc diameter }(\mathrm{m}) ; C \text { is the floc strength co-efficient; } G \text { is the } \\
\text { average velocity gradient }\left(\mathrm{s}^{-1}\right) \text { and } \gamma \text { is the stable floc size constant, an exponent } \\
\text { dependent upon floc break-up mode and the size of eddies that causes the breakage. } \\
\text { A plot of the maximum floc size remaining against the average velocity gradient } \\
\text { gives a line with a characteristic slope indicative of floc strength and break-up mode. }\end{array}$ \\
\hline & Ultrasonics & $\begin{array}{l}\text { Application of a controllable ultrasonic field to a floc } \\
\text { suspension and observe floc erosion (Wen and Lee, } \\
\text { 1998; Chu et al., 2001). }\end{array}$ & $\begin{array}{l}\frac{\delta}{\phi}=\frac{-0.78 k^{0.5} \Delta \tau}{\left.d_{f o}{ }^{-D / 3} D \frac{d y}{d j}\right|_{j \rightarrow 0}} \\
\delta \text { is the floc binding strength }\left(\mathrm{J} \mathrm{m} \mathrm{m}^{-2}\right), \phi \text { is the power of the ultrasonic field per floc's } \\
\left.\text { volume and time ( } \mathrm{W} \mathrm{m}^{-3} \mathrm{~s}\right), \Delta \tau \text { is the ultrasonic time }(\mathrm{s}), d_{f o} \text { is the floc size before } \\
\begin{array}{l}\text { sonification }(\mathrm{m}), d_{f o} \text { is the floc size after sonification }(\mathrm{m}) k \text { is the proportionality } \\
\left.\text { constant (the ratio of the floc's cross-sectional area and } d_{f}^{2 D / 3}\right), D_{f} \text { is the floc fractal } \\
\text { dimension and } j \text { is the time of ultrasonification }(\mathrm{s}) .\end{array}\end{array}$ \\
\hline
\end{tabular}




\begin{tabular}{|c|c|c|c|}
\hline & Multigrid mixer & $\begin{array}{l}\text { Flocs exposed to hydrodynamic stress from a } \\
\text { controllable oscillatory mixer (Bache at al., 1999). Flocs } \\
\text { placed in a vibrating column and subjected to varying } \\
\text { amounts of oscillation. The vibration is converted into an } \\
\text { energy input for the system. }\end{array}$ & $\begin{array}{l}\sigma \approx \frac{\rho_{w} \varepsilon^{3 / 4} d^{1 / 3}}{v^{1 / 4}} \quad \text { Equation } 5 \\
\begin{array}{l}\sigma \text { is the floc strength }\left(\mathrm{N} \mathrm{m}^{-2}\right), \rho_{w} \text { is the density of water }\left(\mathrm{kg} \mathrm{m}^{-3}\right), \varepsilon \text { is the energy } \\
\text { dissipation at height of floc rupture }\left(\mathrm{m}^{2} \mathrm{~s}^{-3}\right), d \text { is the floc diameter }(\mathrm{m}) .\end{array}\end{array}$ \\
\hline $\begin{array}{l}\text { Microscopic } \\
\text { techniques }\end{array}$ & Micromechanics & $\begin{array}{l}\text { The breaking force required to pull apart a single floc in } \\
\text { the tensile mode (Yeung and Pelton, 1996). }\end{array}$ & 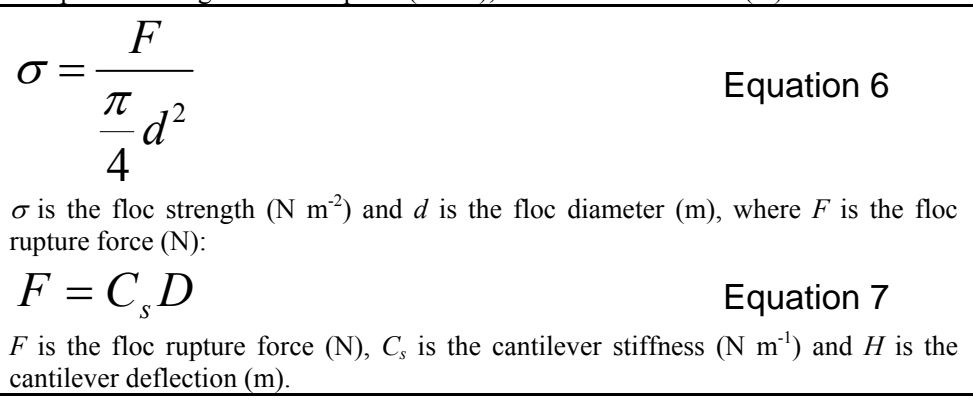 \\
\hline & $\begin{array}{l}\text { Micromanipulatio } \\
\mathrm{n}\end{array}$ & $\begin{array}{l}\text { The squeezing of a single aggregate in suspension } \\
\text { between a glass slide and a fibre optic probe until floc } \\
\text { breakage using a force transducer (Zhang } \text { et al., 1999). }\end{array}$ & $\begin{array}{l}F=K\left(W_{0}-W\right) \quad \text { Equation } 8 \\
F \text { is the floc breaking force }(\mathrm{N}), K \text { is the sensitivity of the force transducer }\left(\mathrm{N} \mathrm{V}^{-1}\right), \\
W \text { is the voltage output }(\mathrm{V}) \text { and } W_{0} \text { is the baseline voltage of the force transducer }(\mathrm{V})\end{array}$ \\
\hline
\end{tabular}


1 Table 2. A review of the different methods employed in shear based techniques for

2 determining floc strength.

\begin{tabular}{|c|c|c|c|c|}
\hline Type of flocs & $\begin{array}{l}\text { Impeller } \\
\text { system }\end{array}$ & $\begin{array}{l}\text { Method of determining } \\
\text { floc size }\end{array}$ & $\begin{array}{l}\text { Shear levels } \\
\text { investigated }\end{array}$ & Reference \\
\hline $\begin{array}{l}\text { Tap water }+ \\
\text { ferric chloride } \\
\text { Tap water }+ \\
\text { ferric chloride }\end{array}$ & $\begin{array}{l}2 \text { L glass tank } \\
\text { with a turbine } \\
\text { type impeller }\end{array}$ & $\begin{array}{l}\text { Photography }+ \text { image } \\
\text { analysis } \\
\text { Non-invasive }\end{array}$ & $G_{a v} 160-500 \mathrm{~s}^{-1}$ & $\begin{array}{l}\text { Leentvaar and } \\
\text { Rebhun (1983) }\end{array}$ \\
\hline Kaolin + alum & $\begin{array}{l}\text { 4 L stirred } \\
\text { vessel } \\
\text { (unknown } \\
\text { impeller type) }\end{array}$ & $\begin{array}{l}\text { Small angle light } \\
\text { scattering (Malvern } \\
\text { Mastersizer 2200) in } \\
\text { situ measurement. } \\
\text { Single pass to waste. }\end{array}$ & $G_{a v} 30-1000 \mathrm{~s}^{-1}$ & Francois (1987) \\
\hline $\begin{array}{l}\text { Polystyrene }+ \\
\text { alum }\end{array}$ & $\begin{array}{l}2.8 \mathrm{~L} \text { baffled } \\
\text { tank with } \\
\text { Rushton } \\
\text { impeller }\end{array}$ & $\begin{array}{l}\text { Small angle light } \\
\text { scattering (Malvern } \\
\text { Mastersizer E) in situ } \\
\text { measurement. } \\
\text { Continuous recycled } \\
\text { pump loop. }\end{array}$ & $\begin{array}{l}100-460 \mathrm{rpm} \\
G_{a v} 50-500 \mathrm{~s}^{-1} \\
G_{\max } 597-5969\end{array}$ & $\begin{array}{l}\text { Spicer et al. } \\
\text { (1998) }\end{array}$ \\
\hline $\begin{array}{l}\text { Activated } \\
\text { sludge }\end{array}$ & $\begin{array}{l}1.2 \mathrm{~L} \text { baffled } \\
\text { mixing tank } \\
\text { with six flat } \\
\text { blade impeller }\end{array}$ & $\begin{array}{l}\text { Small angle light } \\
\text { scattering (Malvern } \\
\text { Mastersizer E) in situ } \\
\text { measurement. } \\
\text { Continuous recycled } \\
\text { pump loop }\end{array}$ & $\begin{array}{l}100-700 \mathrm{rpm} \\
G_{a v} 19.4-444 \mathrm{~s}^{-1}\end{array}$ & $\begin{array}{l}\text { Biggs and Lant } \\
(2000)\end{array}$ \\
\hline $\begin{array}{l}\text { Bentonite }+ \\
\text { alum }\end{array}$ & $\begin{array}{l}\text { Jar tester } \\
\text { (unknown } \\
\text { volume and }\end{array}$ & $\begin{array}{l}\text { Video camera }+ \text { image } \\
\text { analysis } \\
\text { Non-invasive }\end{array}$ & $\begin{array}{l}30-150 \mathrm{rpm} \\
G_{a v} 9-33 \mathrm{~s}^{-1}\end{array}$ & $\begin{array}{l}\text { Bouyer et al. } \\
\text { (2001) }\end{array}$ \\
\hline
\end{tabular}




\begin{tabular}{|c|c|c|c|c|}
\hline & impeller type) & measurement & $G_{\max } 35-360$ & \\
\hline Humic + alum & $\begin{array}{l}2 \text { L square } \\
\text { beaker with } \\
\text { single flat blade } \\
\text { impeller }\end{array}$ & $\begin{array}{l}\text { Video camera + image } \\
\text { analysis. } \\
\text { Non-invasive } \\
\text { measurement }\end{array}$ & $G_{a v} 10-400 \mathrm{~s}^{-1}$ & $\begin{array}{l}\text { Bache and } \\
\text { Rasool (2001) }\end{array}$ \\
\hline $\begin{array}{l}\text { Sewage sludge } \\
+ \text { cationic } \\
\text { polymer }\end{array}$ & $\begin{array}{l}\text { Couette } \\
\text { flocculator } \\
\text { powered by } \\
\text { variable speed } \\
\text { motor }\end{array}$ & $\begin{array}{l}\text { Image analysis with } \\
\text { flocs removed ex situ }\end{array}$ & $G_{a v} 10-400 \mathrm{~s}^{-1}$ & $\begin{array}{l}\text { Wu et al. } \\
\text { (2003) }\end{array}$ \\
\hline $\begin{array}{l}\text { Kaolin }+ \text { alum/ } \\
\text { polyaluminium } \\
\text { chloride }\end{array}$ & $\begin{array}{l}1 \mathrm{~L} \text { jar test } \\
\text { beaker with } \\
\text { single flat blade } \\
\text { impeller }\end{array}$ & $\begin{array}{l}\text { Photometric dispersion } \\
\text { analyser (PDA). } \\
\text { Continuous re-cycled } \\
\text { pump loop }\end{array}$ & $\begin{array}{l}50-400 \mathrm{rpm} \\
G_{a v} 23-520 \mathrm{~s}^{-1}\end{array}$ & $\begin{array}{l}\text { Gregory and } \\
\text { Dupont (2001) } \\
\text { \& Fitzpatrick et } \\
\text { al. (2003). }\end{array}$ \\
\hline
\end{tabular}


1 Table 3. The value of the floc strength constants and coefficients obtained from shear

2 based techniques.

\begin{tabular}{|c|c|c|c|c|}
\hline Type of floc & $\begin{array}{l}\text { Coagulant type and } \\
\text { dose }\end{array}$ & $\begin{array}{l}\text { Floc strength } \\
\text { coefficient } \\
\text { value, } \log C\end{array}$ & $\begin{array}{l}\text { Floc strength } \\
\text { constant, } \gamma\end{array}$ & Reference \\
\hline Alum sludge & $\begin{array}{l}\text { Cationic polymer (PL- } \\
320 \text { ) } \\
0 \rightarrow 30 \mathrm{mg} \mathrm{L}^{-1}\end{array}$ & $2.4 \rightarrow 5.9$ & N/A & Wu et al. (2003) \\
\hline $\begin{array}{l}\text { Ferric } \\
\text { hydroxide } \\
\text { precipitate in } \\
\text { sewage effluent }\end{array}$ & $\begin{array}{l}\text { Ferric chloride } \\
10 \mathrm{mg} \mathrm{L}^{-1} \text { as Fe } \\
\text { Ferric chloride + anionic } \\
\text { polymer } \\
10 \mathrm{mg} \mathrm{L}^{-1} \text { as Fe } \\
+3 \mathrm{mg} \mathrm{L}^{-1} \text { polymer }\end{array}$ & 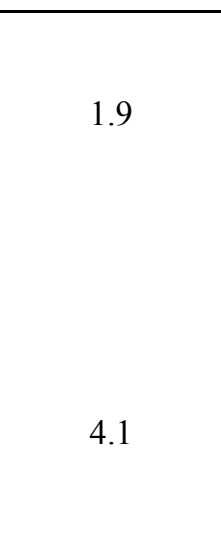 & 0.29 & $\begin{array}{l}\text { Leentvaar and } \\
\text { Rebhun (1983) }\end{array}$ \\
\hline $\begin{array}{l}\text { Ferric } \\
\text { hydroxide } \\
\text { precipitate in } \\
\text { tap water }\end{array}$ & $\begin{array}{l}\text { Ferric chloride } \\
10 \mathrm{mg} \mathrm{L}^{-1} \text { as Fe }\end{array}$ & 2.5 & 0.51 & \\
\hline $\begin{array}{l}\text { Alumino-humic } \\
\text { (commercial } \\
\text { humic solution) }\end{array}$ & Al based coagulant & 3.1 & 0.44 & $\begin{array}{l}\text { Bache et al. } \\
\text { (1999) }\end{array}$ \\
\hline $\begin{array}{l}\text { Alumino-humic } \\
\text { in low } \\
\text { alkalinity and } \\
\text { high colour } \\
\text { water }\end{array}$ & $\begin{array}{l}\text { Al based coagulant } \\
2.4 \mathrm{mg} \mathrm{L}^{-1} \text { as } \mathrm{Al} \\
2.7 \mathrm{mg} \mathrm{L}^{-1} \text { as } \mathrm{Al} \\
4.7 \mathrm{mg} \mathrm{L}^{-1} \text { as Al } \\
5.4 \mathrm{mg} \mathrm{L}^{-1} \text { as } \mathrm{Al} \\
2.5 \mathrm{mg} \mathrm{L}^{-1} \text { as } \mathrm{Al}+\end{array}$ & $\begin{array}{l}3.8 \\
3.4 \\
3.6 \\
3.6 \\
3.8\end{array}$ & $\begin{array}{l}0.61 \\
0.63 \\
0.57 \\
0.52 \\
0.44\end{array}$ & $\begin{array}{l}\text { Bache and Rasool } \\
\text { (2001) }\end{array}$ \\
\hline
\end{tabular}




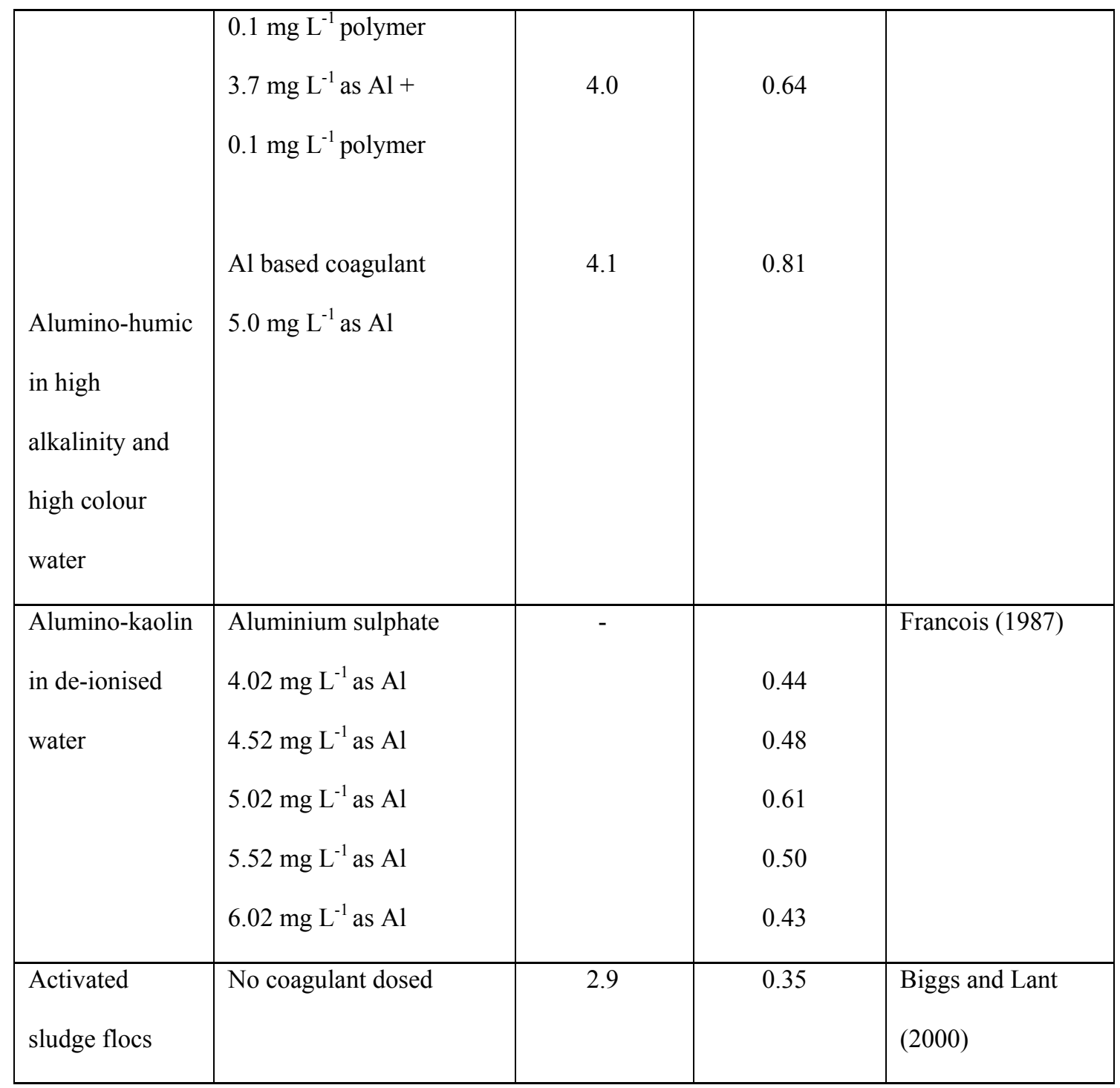

2 
1 Table 4. The general trends observed in floc strength tests*.

\begin{tabular}{|l|l|}
\hline Floc characteristic & Trend observed \\
\hline Floc size & Floc size increases $\rightarrow$ floc strength decreases \\
\hline Coagulant dose & Optimum coagulant dose for floc strength \\
\hline Polymer addition & Biological flocs: \\
& Addition of polymer $\rightarrow$ floc strength decreases \\
& Chemical flocs: \\
& Addition of polymer $\rightarrow$ floc strength increases \\
\hline Type of floc & Bridging particle flocs $>$ charge neutralised \\
& particle flocs $>$ complexation flocs (e.g. \\
\hline & NOM/coagulant) \\
\hline * for this table, the symbol ' $>$ ' indicates where flocs were stronger than another type of floc.
\end{tabular}

3

4

5

6

7

8

9

10

11

12

13

14

15

16

17

18

19 
1 Table 5. Floc strength estimates using a variety of different methods.

\begin{tabular}{|c|c|c|c|c|}
\hline Method & Type of Floc & Floc Size, $\mu \mathrm{m}$ & $\begin{array}{l}\text { Floc Strength } \\
\text { Estimate, } \mathbf{N ~ m}^{-2}\end{array}$ & Reference \\
\hline $\begin{array}{l}\text { Oscillating } \\
\text { multigrid mixer }\end{array}$ & Alumino-humic flocs & $\begin{array}{l}238 \\
182 \\
143 \\
120\end{array}$ & $\begin{array}{l}0.08 \\
0.16 \\
0.29 \\
0.42\end{array}$ & $\begin{array}{l}\text { Bache et al. } \\
\text { (1999) }\end{array}$ \\
\hline $\begin{array}{l}\text { Oscillating } \\
\text { multigrid mixer }\end{array}$ & $\begin{array}{l}\text { Rice starch } \\
\text { aggregated at } \\
\text { isoelectric point } \\
\text { (IEP) } \\
\text { Latex aggregated at } \\
\text { IEP }\end{array}$ & $\begin{array}{l}1100 \\
600 \\
\end{array}$ & $\begin{array}{c}1.0 \\
\\
\\
\\
\\
\\
0.9\end{array}$ & $\begin{array}{l}\text { Bache et al. } \\
\text { (1997) }\end{array}$ \\
\hline Micromechanics & $\begin{array}{l}\text { Polymer A - calcium } \\
\text { carbonate flocs } \\
\text { Polymer B - calcium } \\
\text { carbonate flocs }\end{array}$ & $\begin{array}{l}25 \\
10\end{array}$ & $\begin{array}{c}100 \\
1000\end{array}$ & $\begin{array}{l}\text { Yeung and } \\
\text { Pelton (1996) }\end{array}$ \\
\hline Micromanipulation & $\begin{array}{l}\text { Latex aggregated at } \\
\text { IEP } \\
\text { Latex aggregated by } \\
\text { Brownian motion }\end{array}$ & $\begin{array}{l}2.5 \\
\\
\\
1.7\end{array}$ & $\begin{array}{l}5.3 \mu \mathrm{N}^{*} \\
3.1 \mu \mathrm{N}^{*}\end{array}$ & $\begin{array}{l}\text { Zhang et al. } \\
\text { (1999) }\end{array}$ \\
\hline
\end{tabular}

